\title{
Pulsatile Release of Bioactive Luteinizing Hormone in Prepubertal Girls: Discordance with Immunoreactive Luteinizing Hormone Pulses
}

\author{
EDWARD O. REITER, DARLENE E. BIGGS, JOHANNES D. VELDHUIS, AND INESE Z. BEITINS
}

Department of Pediatrics, Baystate Medical Center, Springfield, Massachusetts 01199 [E.O.R., D.E.B.]; Department of Medicine, University of Virginia Medical School, Charlottesville, Virginia 22908 [J.D.V.]; and Department of Pediatrics of the University of Michigan Medical Center, Ann Arbor, Michigan 48109 [I.Z.B.]

\begin{abstract}
An assessment of pulsatile secretion of luteinizing hormone (LH), measured by both immunoassay (I-LH) and rat interstitial cell testosterone production bioassay (B-LH), as well as of folicle-stimulating hormone and glycoprotein hormone $\alpha$-subunit was carried out in seven normal prepubertal and six normal premenarcheal pubertal girls. Samples were obtained at 20 -min intervals for a 6 - $h$ period. The hormone secretion profiles were analyzed by several computerized methods yielding pulse frequency and amplitude, interpulse basal levels, and percentage increments, with bio/immuno ratios calculated for peak and basal concentrations. In these prepubertal girls, mean B-LH levels were $12 \%$ of $\mathrm{I}-\mathrm{LH}$, with $\mathrm{B} / \mathrm{I}$ ratio of $0.13 ; 30 \%$ of samples were below assay sensitivity $(0.10$ $\mathrm{mIU} / \mathrm{ml})$ for B-LH, but all I-LH $(1.25 \mathrm{mIU} / \mathrm{ml})$ were detectable. In the pubertal group, B-LH levels were $30 \%$ of $\mathrm{I}-\mathrm{LH}$, with mean B/I ratio of 0.24 and undetectable BLH in $29 \%$ of samples. Pulsatile secretion in prepubertal girls was found in five of seven (1/150 min) for B-LH and six of seven (1/212 min) for I-LH; only two of six pubertal girls had detectable pulses. Discordance of B- and I-LH pulses were frequent, with $56 \%$ of B-LH pulses lacking an I-LH pulse and $47 \%$ of I-LH pulses not having a B-LH pulse. These data demonstrate that 1) both B- and I-LH are secreted episodically in prepubertal girls; 2) I-LH-like material is present in higher concentrations than B-LH in these girls; and 3) substantial discordance of B- and I-LH pulses exist. Such findings lend further support for molecular heterogeneity of pituitary gonadotropins during the pubertal process and suggest that changes of biopotency may be important functional regulators of the early pubertal process. (Pediatr Res 21: 409-413, 1987)
\end{abstract}

Abbreviations

LH, luteinizing hormone

FSH, follicle-stimulating hormone

RIA, radioimmunoassay(s)

B-LH, bioactive luteinizing hormone

I-LH, immunoreactive luteinizing hormone

GnRH, gonadotropin-releasing hormone

The mechanisms responsible for the initiation and tempo of puberty remain elusive. It is currently believed that central to

Received September 8, 1986; accepted December 2, 1986.

Reprints Edward O. Reiter, M.D., Department of Pediatrics, Baystate Medical Center, 759 Chestnut Street, Springfield, MA 01199.

Supported by a research grant from Baystate Medical Center (E.O.R., D.E.B.) RCDA-1KO4HDOO634 (J.D.V.), and HD18512 (I.Z.B.) the onset of puberty is an increase in the frequency, as well as amplitude, of GnRH pulses from the hypothalamus which is translated into gonadotropin secretory pulses from the pituitary. Increased LH pulse frequency and amplitude, as measured by ILH have been demonstrated in early pubertal children (1-4). In addition, the mean I-LH levels have been shown to rise with advancement of puberty in both cross-sectional and longitudinal studies $(5,6)$.

Pituitary gonadotropins are known to be heterogeneous. Therefore, in addition to changes in the quantity of gonadotropins, as measured by immunoassays, the quality of gonadotropins as measured by in vitro bioassays and on isoelectric focusing have been shown to change (7-10). In general the B-LH levels in serum have exceeded those of I-LH in both cross-sectional (11) and longitudinal studies during puberty in both boys and girls (12). In mature men and women the B/I ratio of $\mathrm{LH}$ is increased during endogenous $\mathrm{LH}$ pulses and there exists an overall concordance between the B-LH and I-LH pulses in excess of $80 \%(7,8)$.

In this study we examined and compared the LH pulse characteristics in normal prepubertal and pubertal girls. In particular, we wished to establish whether 1) B-LH was secreted in episodic pulses that exceeded the amplitude of I-LH pulses thereby making detection more accurate and 2) the B- and I-LH was secreted synchronously.

\section{MATERIALS AND METHODS}

Subjects. Seven healthy, normal prepubertal girls and six premenarcheal pubertal girls were recruited. The prepubertal girls were Tanner breast stage 1 and had a mean age of $8.6 \pm 0.2$ (SEM) yr. The premenarcheal girls had either Tanner breast stage II $(n=4)$ and were $10.7 \pm 0.8$ yr old or Tanner breast stage III/ IV and were $12.0 \pm 3.8 \mathrm{yr}$ old. All had normal developmental and health histories, physical examinations, and were not taking medications.

The study had been approved by the Human Subjects Committee of Baystate Medical Center and details were explained to the children and their parents. The volunteers and their parents signed an informed consent form before participation in the study.

Study protocol. All of the girls had an intravenous needle placed in a forearm vein $30 \mathrm{~min}$ before the sampling was started. Subjects were resting comfortably and did not appear anxious or distressed. Blood samples were collected every $20 \mathrm{~min}$ for a total of $360 \mathrm{~min}$. The sera were separated and kept at $-20^{\circ} \mathrm{C}$ until assayed.

Assays. In each sample LH, FSH, and glycoprotein hormone $\alpha$-subunit were measured by specific RIA the characteristics of which have been previously published (13). B-LH was measured by means of the rat interstitial cell assay $(11,13)$ in each sample. 
All of the samples from each subject were included in one assay. Integrated serum pools from the whole study were used for the measurement of serum $E_{2}$ and estrone sulfate by means of sensitive and specific RIA (14).

The assay for serum I-LH was a double antibody RIA utilizing iodinated LER960 and IRP-2 hMG (Second International Reference Preparation of Human Menopausal Gonadotropin) as the reference standard. The same standard was used for the estimation of serum I-FSH and B-LH. The respective sensitivities of the I-LH and B-LH assays were 1.25 and $0.1 \mathrm{mIU} / \mathrm{ml}$, respectively. The $\alpha$-subunit was measured by means of a specific RIA which had a sensitivity of $37 \mathrm{pg} / \mathrm{ml}$ using LER 1793 for assay standard and LER 1946 for iodination material (13).

Statistical analyses. The serum LH secretion profiles were analyzed by several methods. We modified the program of Santen and Bardin (15) setting a threshold for minimum increase from nadir to peak of more than four times the pertinent individual intraassay coefficient of variation as the requirement for definition of a pulse. Such a criterion reduces the falsepositive rate to approximately $1 \%$. The intraassay coefficients of variation used for this analysis were: $8.1 \%$ for B-LH over the range of 2 to $8 \mathrm{mIU} / \mathrm{ml}, 16.3 \%$ over the range of 1 to $2.0 \mathrm{mIU} /$ $\mathrm{ml}$, and $18.3 \%$ over the range of 0.1 to $1.0 \mathrm{mIU} / \mathrm{ml} ; 9.7,8.1$, and $10.1 \%$ for the LH, FSH, and $\alpha$-subunit immunoassays in the relevant range for the potency estimates made in sera from these girls.

The output from the Santen and Bardin (15) program also provides percentage increments of pulses (nadir-to-peak increases), integrated area under the gonadotropin curve over the sampling period, and the mean level for the entire sampling. Smoothed overall baseline concentrations to correct for presence of pulses were estimated by a weighted moving average across all the data series using a program of Merriam and Wachter (16). The method of Clifton and Steiner (17) which performs iterative data scans to identify significant pulses exceeding a threshold value which undergoes continuing adjustment to avoid missing true pulses but minimizing the false influence of assay noise was also utilized. This latter analytic technique was used to check the modified methodology of Santen and Bardin (15) and demonstrated high concordance (approximately $85 \%$ ) of pulse designation.

Pulse data are given as mean \pm SE. Comparisons between Iand B-LH values were analyzed by within-subject comparisons using a paired two-tailed Student's $t$ test. I- and B-LH pulses were considered concordant whenever the pulses overlapped in time.

\section{RESULTS}

Subjects. The group of seven prepubertal girls have to be considered "late" prepubertal. In a previous study we characterized B-LH in 15 prepubertal girls who were $6.2 \pm 0.8 \mathrm{yr}$ old with serum $E_{2}$ levels of $3.9 \pm 0.4 \mathrm{pg} / \mathrm{ml}$ (11). Although the present group of girls also had Tanner breast stage I on physical examination, they were older (mean of $8.6 \mathrm{yr}$ ) and had significantly higher serum $\mathrm{E}_{2}$ levels $[7.7 \pm 0.1(\mathrm{SE}) \mathrm{pg} / \mathrm{ml}(p<0.001)]$. Serum estrone sulfate levels were also higher $(167 \pm 11$ versus $97 \pm \mathrm{pg} /$ $\mathrm{ml}$ ) in the older group.

Table 1. Characteristics of pulsatile secretion of bioactive $L H$ relative to immunoreactive $L H$ in prepubertal girls

\begin{tabular}{|c|c|c|c|c|c|c|c|c|c|}
\hline \multirow[b]{2}{*}{ Subject } & \multirow{2}{*}{$\begin{array}{c}\text { Mean } \\
(\mathrm{mIU} / \mathrm{ml})\end{array}$} & \multirow{2}{*}{$\begin{array}{c}\text { Area } \\
(\mathrm{mlU} / \mathrm{ml} \cdot \mathrm{min})\end{array}$} & \multirow{2}{*}{$\begin{array}{l}\text { Pulse frequency* } \\
\text { (no. } / 6 \mathrm{~h})\end{array}$} & \multicolumn{2}{|c|}{$\begin{array}{c}\text { Amplitude } \\
\text { characteristics }\end{array}$} & \multirow{2}{*}{$\begin{array}{l}\text { Interpulse Basal } \\
(\mathrm{mIU} / \mathrm{ml})\end{array}$} & \multirow[b]{2}{*}{$\mathrm{B} / \mathrm{I}$} & \multirow{2}{*}{$\begin{array}{c}\text { Basal } \\
\mathrm{B} / \mathrm{I}\end{array}$} & \multirow{2}{*}{$\begin{array}{c}E_{2} \\
(p g / m l)\end{array}$} \\
\hline & & & & Peak & $\%$ Increment & & & & \\
\hline \multicolumn{10}{|l|}{1} \\
\hline B-LH & 0.73 & 248 & 3 & 1.3 & 118 & 0.67 & 0.21 & 0.21 & 8 \\
\hline I-LH & 3.5 & 1126 & 1 & 4.6 & 71 & 3.2 & & & \\
\hline \multicolumn{10}{|l|}{2} \\
\hline B-LH & 0.36 & 120 & 3 & 0.9 & 216 & 0.51 & 0.13 & 0.10 & 10 \\
\hline $\mathrm{I}-\mathrm{LH}$ & 2.89 & 974 & 2 & 5.1 & 107 & 2.6 & & & \\
\hline \multicolumn{10}{|l|}{3} \\
\hline B-LH & 0.50 & 168 & 2 & 0.8 & 312 & 0.34 & 0.09 & 0.05 & 8 \\
\hline I-LH & 5.84 & 1862 & 2 & 7.3 & 56 & 5.3 & & & \\
\hline \multicolumn{10}{|l|}{4} \\
\hline B-LH & 0.63 & 214 & 2 & 1.5 & 156 & 0.63 & 0.22 & 0.15 & 9 \\
\hline I-LH & 2.90 & 989 & 2 & 4.3 & 90 & 2.7 & & & \\
\hline \multicolumn{10}{|l|}{5} \\
\hline B-LH & 0.63 & 214 & 2 & 1.2 & 78 & 0.59 & 0.16 & 0.12 & 7 \\
\hline $\mathrm{I}-\mathrm{LH}$ & 3.96 & 1334 & 2 & 4.8 & 60 & 4.0 & & & \\
\hline \multicolumn{10}{|l|}{6} \\
\hline B-LH & 0.10 & 36 & 0 & IND $\dagger$ & 0 & 0.10 & 0.04 & 0.02 & 5 \\
\hline I-LH & 2.71 & 922 & 1 & 4.2 & 43 & 2.6 & & & \\
\hline \multicolumn{10}{|l|}{7} \\
\hline B-LH & 0.10 & 36 & 0 & IND & 0 & 0.10 & 0.03 & 0.02 & 7 \\
\hline $\mathrm{I}-\mathrm{LH}$ & 3.81 & 1296 & 0 & IND & 0 & 3.6 & & & \\
\hline \multicolumn{10}{|c|}{ Mean \pm SEM } \\
\hline B-LH & $0.43 \pm 0.10$ & $148 \pm 33$ & 2.4 & $1.1 \pm 0.13$ & $176 \pm 41$ & $0.42 \pm 0.10$ & $0.13 \pm 0.03$ & $0.10 \pm 0.03$ & $7.7 \pm 0.6$ \\
\hline I-LH & $3.6 \pm 0.4$ & $1215 \pm 124$ & 1.7 & $5.1 \pm 0.5$ & $71 \pm 10$ & $3.4 \pm 0.4$ & & & \\
\hline
\end{tabular}

* Frequency in whom significant pulses were detected.

$\dagger$ As no significant pulse was detected, peak amplitude was indeterminate. 
Table 2. Characteristics of pulsatile secretion of bioactive $L H$ relative to immunoreactive LH in six pubertal girls (mean \pm SEM)

\begin{tabular}{|c|c|c|c|c|c|c|c|c|c|}
\hline & \multirow{2}{*}{$\begin{array}{c}\text { Mean } \\
(\mathrm{mIU} / \mathrm{ml})\end{array}$} & \multirow{2}{*}{$\begin{array}{c}\text { Area } \\
(\mathrm{mIU} / \mathrm{ml} \cdot \mathrm{min})\end{array}$} & \multirow{2}{*}{$\begin{array}{l}\text { Pulse frequency* } \\
\text { (no. 6/h) }\end{array}$} & \multicolumn{2}{|c|}{$\begin{array}{c}\text { Amplitude } \\
\text { characteristics }\end{array}$} & \multirow{2}{*}{$\begin{array}{l}\text { Interpulse basal } \\
(\mathrm{mIU} / \mathrm{ml})\end{array}$} & \multirow[b]{2}{*}{$\mathrm{B} / \mathrm{I}$} & \multirow{2}{*}{$\begin{array}{c}\text { Basal } \\
\mathrm{B} / \mathrm{I}\end{array}$} & \multirow{2}{*}{$\begin{array}{c}\mathrm{E}_{2} \\
(\mathrm{pg} / \mathrm{ml})\end{array}$} \\
\hline & & & & Peak & $\%$ Increment & & & & \\
\hline B-LH & $1.61 \pm 0.94$ & $541 \pm 316$ & 3 & $2.5 \pm 1.3$ & $164 \pm 109$ & $1.4 \pm 0.8$ & $0.24 \pm 0.09$ & $0.25 \pm 0.10$ & $19.8 \pm 7.7$ \\
\hline I-LH & $5.24 \pm 1.02$ & $1772 \pm 346$ & 1 & $7.1 \pm 1.4$ & $66 \pm 14$ & $4.8 \pm 1.1$ & & & \\
\hline
\end{tabular}

* Frequency in subjects in whom significant pulses were detected.

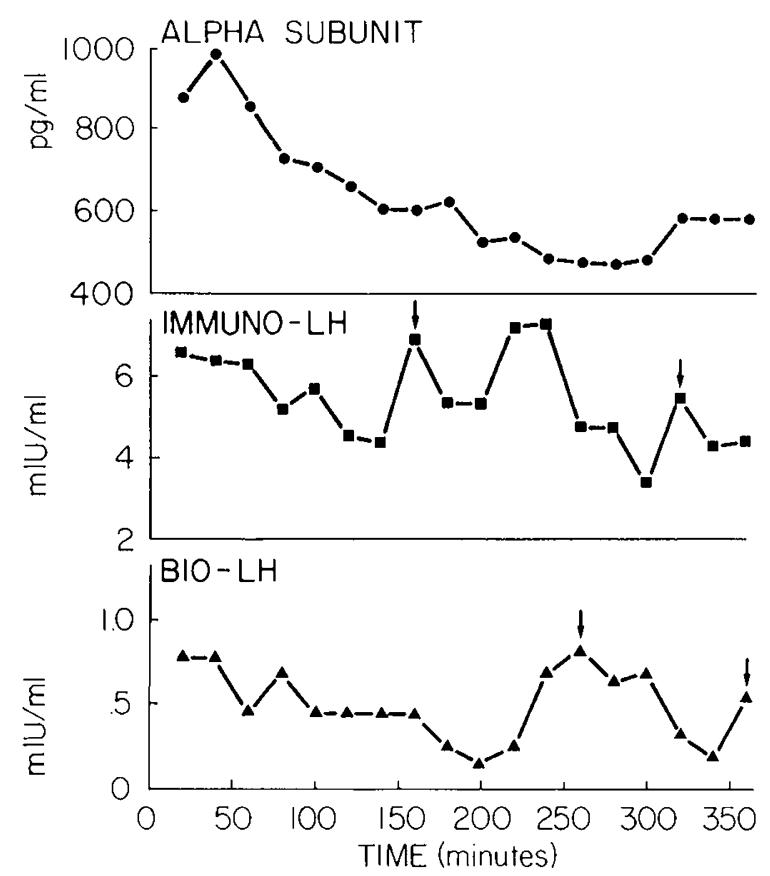

Fig. 1. Data from one of the normal prepubertal girls showing all samples from the 6-h assessment of $\alpha$-subunit I-LH and B-LH. The arrows indicate significant putses.

The pubertal group were clearly more advanced in terms of sexual development (Tanner II to IV breast stage), age (10.7 \pm $0.8 \mathrm{yr}$.), and hormonal values (serum $\mathrm{E}_{2}: 19.8 \pm 7.7 \mathrm{pg} / \mathrm{ml}$ and serum estrone sulfate $251 \pm 46 \mathrm{pg} / \mathrm{ml}$.

Mean and integrated concentrations of B-LH and I-LH (Tables $I$ and 2 . In the normal prepubertal girls (Table 1), mean serum concentration of $\mathrm{B}-\mathrm{LH}$ was only $12 \%$ of $\mathrm{I}-\mathrm{LH}$; the integrated area under the time concentration curve showed a similar discrepancy. These findings yielded a mean $\mathrm{B} / \mathrm{I}$ ratio of $0.13 \pm 0.03$. Thirty percent (38 of 126$)$ of the samples were at or below the limit of assay sensitivity $(0.10 \mathrm{mIU} / \mathrm{ml})$ for B-LH, but all I-LH samples were detectable ( $>1.25 \mathrm{mIU} / \mathrm{ml})$.

In the small mixed group of pubertal girls (Table 2), mean B$\mathrm{LH}$ levels were approximately $30 \%$ of I-LH values. This was also reflected in the area under the curve, with a mean overall $\mathrm{B} / \mathrm{I}$ ratio of $0.24 \pm 0.09$. Twenty-nine percent (31 of 108) of the samples showed no detectable B-LH, while all I-LH samples were measurable.

Pulsatile secretion of B-LH and I-LH. Quantitative analysis of pulse frequency of B-LH and I-LH is shown in Tables 1 and 2. In the prepubertal girls, pulses were detected in five of seven by bioassay and in six of seven by immunoassay studies. In these children in whom pulses were found, they occurred at a frequency of $2.4 / 6 \mathrm{~h}$ (once per $150 \mathrm{~min}$ ) for B-LH and 1.7/6 h (once per $212 \mathrm{~min}$ ) for I-LH. The increment during B-LH pulses was nearly 2 -fold, while the I-LH pulses rose by around $70 \%$.

Surprisingly, pulsatile secretion was detected in only two of the six pubertal girls (one Tanner II, the other Tanner IV). In those children, the B-LH spikes occurred at a frequency of $3 / 6$
Table 3. Discordance of B-LH, I-LH, and glycoprotein hormone $\alpha$-subunit pulses

\begin{tabular}{|c|c|c|c|c|}
\hline & \multirow{2}{*}{$\begin{array}{c}\text { Total no. } \\
\text { of } \\
\text { LH pulses }\end{array}$} & \multicolumn{3}{|c|}{ No. discordant with (\%) } \\
\hline & & B-LH & $\mathrm{I}-\mathrm{LH}$ & $\alpha$ \\
\hline \multicolumn{5}{|c|}{ Prepubertal $(n=7)$} \\
\hline B-LH & 12 & & $6(50 \%)^{*}$ & $12(100 \%) \dagger$ \\
\hline I-LH & 10 & $4(40 \%) \ddagger$ & & $10(100 \%)$ \\
\hline \multicolumn{5}{|c|}{ Pubertal $(n=6)$} \\
\hline B-LH & 6 & & $4(67 \%)$ & $4(67 \%)$ \\
\hline I-LH & 5 & $3(60 \%)$ & & $3(60 \%)$ \\
\hline \multicolumn{5}{|c|}{ Summary } \\
\hline B-LH & 18 & & $10(56 \%)$ & $16(89 \%)$ \\
\hline I-LH & 15 & $7(47 \%)$ & & $13(87 \%)$ \\
\hline
\end{tabular}

$* \%$ of B-LH peaks without a significant I-LH peak.

$\dagger \%$ of I-LH or B-LH peak with a significant $\alpha$-subunit peak.

$\ddagger \%$ of I-LH peaks without a significant B-LH peak.

h (once per $120 \mathrm{~min}$ ), but I-LH occurred only once per $6 \mathrm{~h}$. As in the younger girls, the incremental change per pulse was greater for B- than I-LH.

When the interpulse basal level is examined, the $\mathrm{B} / \mathrm{I}$ ratio $(0.10 \pm 0.03)$ is significantly lower $(p<0.007)$ than the overall mean $\mathrm{B} / \mathrm{I}$ in the prepubertal girls. In the few pulses which were concordant, the mean $\mathrm{B} / \mathrm{I}$ of $0.17 \pm 0.03$ was greater, although not significantly ( $p=0.077)$, than in the interpulse phase. In the pubertal girls, with little evident pulsatile activity, the interpulse basal levels are similar to the mean levels of $\mathrm{LH}$, and $\mathrm{B} / \mathrm{I}$ ratios do not differ.

Discordance of B-LH and I-LH pulses (Table 3; Fig. I). When concordance of pulses measured by bioassay or immunoassay was assessed, substantive differences were noted. When significant B-LH pulses were detected, $56 \%$ lacked an associated I-LH pulse; conversely, $47 \%$ of I-LH did not have a simultaneous BLH rise. Asynchrony was evident both in the prepubertal and pubertal groups.

$F S H$. Mean FSH levels $(3.3 \pm 0.7 \mathrm{mIU} / \mathrm{ml}, \mathrm{IRP}-2-\mathrm{hM} 6)$ in the seven prepubertal girls were significantly $(p<0.006)$ lower than in the six pubertal girls $(7.1 \pm 0.9)$. Significant pulses were demonstrable in four of seven prepubertal girls, occurring at a frequency of $2 / 6 \mathrm{~h}$ in those subjects; FSH pulses were found in three of six pubertal girls, occurring at a frequency of $1.3 / 6 \mathrm{~h}$ when found.

Glycoprotein $\alpha$-subunit. Mean $\alpha$-subunit levels (402 $\pm 42 \mathrm{pgml})$ in the prepubertal girls did not differ from the pubertal girls (504 $\pm 116)$. The $\alpha$-subunit data were analyzed using the same criteria as for B- and I-LH and FSH. There were very few significant $\alpha$ pulses (four in 13 six-h sampling periods) and only one of four occurred with a significant I-LH spike. The subunit measurements seem to provide a stable background of minimally fluctuating concentrations in children.

\section{DISCUSSION}

Research protocols regarding pubertal development have utilized gonadotropin RIA estimates. However, recent studies of 
hormone heterogeneity $(19,20)$ indicate that the regulation of the pubertal process is a much more complex phenomenon involving changes not only in a quantity of the gonadotropins released but also the degree of glycosylation and/or changes in the tertiary structure of the gonadotropin molecule (21). The sugar residues not only influence the isoelectric point and receptor binding potential of the gonadotropin molecule but also protect the molecules from hepatic and renal uptake and enzymatic degradation thereby prolonging circulation time (22). The relative proportions of the isohormones appear to regulate the $\mathrm{B} / \mathrm{I}$ ratio of the gonadotropins and some biologically inert but immunologically detectable forms may in fact act as target cell inhibitors by inappropriate binding and occupation of receptor sites.

Previous studies of newborn girls revealed pulsatile B-LH release on day 7 of life, a period of relatively high hypothalamicpituitary-gonadal axis activity (23). In this study, we have demonstrated the detectability of B-LH pulses during the prepubertal and pubertal period in healthy, normal girls. The B-LH pulse frequency and amplitude have been compared to I-LH-derived data and the congruity of B-LH and I-LH pulses has been determined.

In pubertal children as well as adults, discrete episodic bursts of I-LH have been recorded about once every 90 to $120 \mathrm{~min}$, with increases in pulse frequency near midcycle in menstruating women and during sleep in pubertal children (7). We do not know whether these pubertal girls, who had fewer pulses than shown in earlier studies (1-4), responded somewhat differently to the experimental milieu. In addition, we would emphasize that very extended sampling sessions (not possible in the present study) may be required to demonstrate absolute differences in $\mathrm{LH}$ pulse frequency.

In prepubertal children, some but not all investigators have found secretory pulses of I-LH (1-4). In a recent definitive study, Jackacki et al. (4) demonstrated that LH was secreted in a pulsatile manner in prepubertal children, with lower amplitude than in more mature individuals. Frequency difference between younger and older subjects is less clear because concentrations of gonadotropins in youth are low and it is often difficult to consistently demonstrate episodic release for methodologic and statistical reasons. In these studies of daytime $\mathrm{LH}$ secretion, we found a pulse frequency of once/150 min for B-LH and once per $212 \mathrm{~min}$ for I-LH. The I-LH levels are similar to those reported by Jackacki et al. (4) during nocturnal sampling in their prepubertal children with significant pulses occurring once every $164 \mathrm{~min}$.

We have previously characterized B-LH secretion patterns in men, in cycling women during the different phases of the menstrual cycle, and in postmenopausal women $(7,8)$. In those subjects, a total percentage discordance between B-LH and I-LH pulses was in the $20-30 \%$ range, with a predominance of the discordance occurring in the situation of a significant I-LH pulse without a B-LH rise (27 to $45 \%$, greatest in the postmenopausal women). Only 12 to $14 \%$ of B-LH spikes occurred without an ILH rise in more than 230 total pulses analyzed in the three studies in adults. Thus, asynchronous release of B- or I-LH is much lower than in the younger subjects in this report, with the exception of the postmenopausal women in whom nearly onehalf of I-LH pulses were not accompanied by a significant B-LH rise. In the prepubertal girls, $46 \%$ of total pulses showed discordance of B- and I-LH, with $50 \%$ having no immunoassayable $\mathrm{LH}$ when a bioactive spike was defined. Additionally, because of the very low potency estimates of B-LH in these girls, the B/I ratios during concordant pulses remained far below unity $(0.17)$, in contrast to the ratios of 2 to 8 for the older subjects (11). It does not appear that the glycoprotein hormone $\alpha$-subunit is secreted concordantly with I-LH so that it could artifically increase I-LH potency (by cross-reacting in the I-LH system), thereby lowering the $\mathrm{B} / \mathrm{I}$ ratio of $\mathrm{LH}$.

The fact that I-LH is clearly measurable before B-LH concen- trations increase is further supported by longitudinal studies conducted in both boys and girls in Geneva (12). In all cases, the I-LH was measurable about 1 yr before B-LH was detected, despite the extreme sensitivity of the bioassay system. However, the B-LH increase correlated well with physiologic signs of puberty, suggesting that the earlier I-LH-like material was biologically inert. Immunoreactive FSH and bioactive FSH concentrations during puberty show a similar relationship (24).

The meaning of these measurement differences are not known. However, each determination, immunoassay or in vitro bioassay, could potentially be detecting different heterogeneous forms. Burstein et al. (25) have evaluated the changes in B/I ratios of LH during puberty. They found that the slopes of I-LH measurements from the sera of young children differed from one person to the next. The RIA systems used are significantly influenced by the choice of the materials such as antibody, radiolabeled $\mathrm{LH}$, and standard. A biological assay is by definition based on the comparison between the effect of an unknown preparation and the effect of the standard preparation on a living organism of surviving tissue (26). Therefore, it is the sum of all inhibitory influences subtracted from all stimulatory influences within the serum. It is known that isoelectric focusing patterns of pituitary gonadotropins from rats (10) and humans (27) collected during different phases of pubertal development revealed gonadotropin heterogeneity with variable immuno- or biopotency. Similar isoelectric patterns from sera of children during puberty remain incomplete, yet it is conceivable that during puberty a greater proportion of acidic LH species with diminished biopotency in in vitro bioassays but prolonged circulation times is present. These forms may be important for organ growth and maturation, whereas those with increased in vitro biopotency and shorter circulation times may contribute to dynamic events such as ovulation. The changes in relative proportion of molecular species of gonadotropins presumably contribute to the regulation of pubertal gonadal maturation.

\section{REFERENCES}

1. Judd HL 1979 Biorhythms of gonadotropins and testicular hormone secretion. In: Krieger DT (ed) Endocrine Rhythms. Raven Press, New York, pp 299 324

2. Parker DC, Judd HL, Rossman LG, Yen SSC 1975 Pubertal sleep-wake patterns of episodic LH, FSH and testosterone release in twin boys. $J$ Clin Endocrinol Metab 40:1099-1 109

3. Penny R, Olambiwonnu NO, Frasier SD 1977 Episodic fluctuations of serum gonadotropins in pre- and post-pubertal girls and boys. J Clin Endocrinol Metab 45:307-311

4. Jackacki RI, Kelch RP, Sauder SE, Lloyd JS, Hopwood NJ, Marshall JC 1982 Pulsatile secretion of luteinizing hormone in children. J Clin Endocrino Metab 55:453-458

5. Grumbach MM, Roth JC, Kaplan SL, Kelch RP 1974 Hypothalamic-pituitary regulation of puberty in man: evidence and concepts derived from clinical research. In: Grumbach MM, Grave GD, Mayer FE (eds) The Control of the onset of puberty, Wiley, New York, pp 115-166

6. Reiter EO, Grumbach MM 1982 Neuroendocrine control mechanisms and the onset of puberty. Ann Rev Physiol 44:595-613

7. Dufau ML, Veldhuis JD, Fraioli F, Johnson ML and Beitins IZ 1983 Mode of secretion of bioactive LH in man. J Clin Endocrinol Metab 57:993-1000

8. Velduis JD, Beitins IZ, Johnson ML, Serabian MA, Dufau ML 1984 Biologically active luteinizing hormone is secreted in episodic pulsations that vary in relation to stage of the menstrual cycle. J Clin Endocrinol Metab 58:10501058

9. Robertson DM, Foulds L, Ellis S 1982 Heterogeneity of rat pituitary gonadotropins on electrofocusing. Differences between sexes and after castration. Endocrinology 111:385-391

10. Chappel SC, Ulloa-Aquirre A, Ramaley J 1983. Sexual maturation in the female rat: time course of the appearance of multiple species of anterior pituitary FSH. Biol Reprod 28:196-205

11. Reiter EO, Beitins IZ, Ostrea TR, Gutai JP 1982 Bioassayable luteinizing hormones during childhood and adolescence and in patients with delayed pubertal development. J Clin Endocrinol Metab 54:155-161

12. Reiter EO, Sizonenko PC, Witt MF, Beitins IZ 1984 Sex differences in the detectability of Bio (B) and Immuno (I)-LH in early pubertal development: a longitudinal study. Pediatr Res 18:175A

13. Beitins IZ, Axelrod L, Ostrea T, Little R, Badger TM 1981 Hypogonadion in a male with an immunologically active, biologically inactive LH: characterization of the abnormal hormone. J Clin Endocrinol Metab 52:1143-1149

14. Franz C, Watson D, Longcope C 1979 Estrone sulfate and dehydroepandros- 
terone sulfate concentrations in normal subjects and men with cirrhosis. Steroids 34:563-573

15. Santen RJ, Bardin CW 1973 Episodic luteinizing hormone secretion in man. Pulse analysis, clinical interpretation, physiologic mechanisms. J Clin Invest 52:2617-2618

16. Merriam GR, Wachter KW 1982 Algorithms for the study of episodic hormone secretion. Am J Physiol 243:E310-E318

17. Clifton DK, Steiner RA 1983 Cyclic detection: a technique for estimating the frequency and amplitude of episodic fluctuations in blood hormone and substrate concentrations. Endocrinology 112:1057-1064

18. Grumbach MM 1980 The neuroendocrinology of puberty. In: Krieger DT, Hughes JC (eds) Neuroendocrinology. Sinauer Assoc, Sunderland, MA, pp $249-258$

19. Wide L 1982 Male and female forms of human follicle-stimulating hormone in serum. J Clin Endocrinol Metab 55:682

20. Foulds LM, Robertson DM 1983 Electrofocusing fractionation and characterization of pituitary folliclc-stimulating hormone in male and female rats. Mol Cell Endocrinol 31:117-130

21. Sherins R, Vaitukaitis J, Chrambach A 1973 Physical characterization of hFSH and its desialylation products on isoelectric focusing and electrophoresis in polyacrylamide gel. Endocrinology 92:1135-1141

22. Bogdanove EM, Campbell GT, Blair ED, Mula ME, Miller AE, Grossman GH 1974 Gonad-pituitary feedback involves qualitative change: androgens alter the type of FSH secreted by rat pituitary. Endocrinology 95:219-228

23. Danon M, Beitins IZ, Velez O, Ostrea T, Crawford JD 1982 Dynamics of bioactive LH during the first seven days of life. Pediatr Res 16:137A

24. Foster CM, Feuillan P, Padmanabhan V, Pescovitz OH, Beitins IZ, Comite F, Shawker TH, Loriaux DL, Cutler GB Jr 1986 Ovarian function in girls with McCune Albright Syndrome. Pediatr Res 20:859-863

25. Burstein S, Schaff-Blass E, Blass J, Rosenfield RL 1985 The changing ratio of bioactive to immunoreactive luteinizing hormone $(\mathrm{LH})$ through puberty principally reflects changing $\mathrm{LH}$ radioimmunoassay dose response characteristics. J Clin Endocrinol Metab 61:508-513

26. Borth R, Diczfalusy E, Heinricks MD 1957 Fundamentals of the statistical analysis of biological assays. Arch F Gynak 188:497-538

27. Wide L 1986 Pituitary FSH of prepubertal children is qualitatively different from that of adults. Proceedings of the 68th Annual Meeting of Endocrine Society, p 160(abstr 516) 